\title{
The Impact of Tidal River Management on Livestock in the Ganges-Brahmaputra Basin
}

\author{
Md. Mahedi Al Masud ${ }^{1,3 *}$, Nurun Naher Moni ${ }^{2}$, Abul Kalam Azad ${ }^{3}$ and Sadhon Chandra Swarnokar \\ ${ }^{1}$ Department of Social Services under the Ministry of Social Welfare, Dhaka 1207, Bangladesh \\ ${ }^{2}$ Economics Discipline, Khulna University, Bangladesh \\ ${ }^{3}$ Environmental Science Discipline, Khulna University, Bangladesh
}

Submission: June 15, 2018; Published: July 19, 2018

*Corresponding author: Md. Mahedi Al Masud, Department of Social Services under the Ministry of Social Welfare, Dhaka 1207, Bangladesh,

Tel: +88-01718-125002; Email: md.mahedi.am@gmail.com

\begin{abstract}
Ganges-Brahmaputra Basin provides several wetlands which are resourceful for rearing livestock as to support coastal community and their livelihoods in the Southwest Bengal delta. Water-logging hampers rural livelihood by damaging agricultural crops, plant, trees, grazing land and reducing livestock. Primarily, Tidal River Management (TRM) is introduced by coastal community to manage tidal river-floodplain ecosystem by way of removing water-logging, increasing navigability of tidal river, improving agriculture and biodiversity of tidal basin, and progressing livestock which lead to human wellbeing. The study selects Bhaina tidal basin from Southwest Bengal delta to assess the impact of TRM on livestock and the contribution of livestock to households' income. The authors collected both quantitative and qualitative data through face to face interview, key informant interview and focus group discussion. This research finds that, households own greater number of livestock after TRM scenario than that of before TRM scenario. Duck achieves the top number (604) followed by hen (378) from bird species. In addition, cow encompasses the peak number (274) that tailed by goat number (162) from four-legged animal. Besides, households' income is reduced by $26 \%$ during TRM case due to effect of salinity and improved by $50 \%$ after TRM case considering before TRM case as the base. Sheep is a newly introduced species (found after TRM event) and buffalo and horse are the rare among selected eight species in the study area. Although grazing land is decreasing due to changing cropping patters, food and fodder are available by improving agriculture and terrestrial biodiversity. The study findings will support policy makers to operate TRM effectively for advancing agriculture, livestock and other ecosystem services to pastoral livelihood in the coastal region.
\end{abstract}

Keywords: TRM scenarios; Livestock; Coastal livelihood; Impact; Bhaina tidal basin; Pastoralists

\section{Introduction}

The Ganges-Brahmaputra Basin is accompanied by diversified occupational pattern and thereby not only depend on agriculture but also depend on homestead vegetation and animal husbandry. Animal husbandry is the second largest income source of household after agriculture that predominantly governs the coastal livelihood [1]. Valuable resources for livestock come from wetland such as place for grazing land, water for drinking, trees for shade and shelter, plants and grass that are fundamental need of animals. Consequently, wetlands are often used more intensively by the pastoralists for supporting their livelihood besides fishing and agro farming [2]. The type of animal, its activity, feed intake, breeding and nourishment of animals in the different life cycle stages wetland are directly or indirectly connected to livelihoods and quality of life in form of pasture, fodder and grains that are eaten by the animals[3]. As livestock virtually requires 5 to 20 times more water per kg product than crop products, it is therefore, obvious that the trend and magnitude of water-logging will have an impact on animal production [4]. Poultry, goat and other larger domestic animals can be feed by domestic water sources such as ponds, subsurface dams, boreholes, and shallow tube wells but the daily food sources come from agrarian cultivation which mostly depend on wetland [5].

The Southwest Bengal delta is one of the climates induced vulnerable zones all over the world $[6,7]$. The shape and structure of the river and floodplain directed by the water regime (e.g. flow depth, velocity, energy) which in turn determine the type and number of animal and plant communities[8]. Although it provides variety of ecosystem services and benefits to the coastal community, large scale recurrent hydro-climatic disaster, land use and occupational changes have made the region more vulnerable that altered coastal dynamics [9-11]. High rate of sedimentation on riverbeds and structural interferences to the flow path of river gradually make this region environmentally 
stressed [12,13]. Hari-Teka River of this region carries a huge amount of sediment that silted on river bed and leads its tidal basin to water-logging by trapping monsoon rain fall inside the basin (natural depression). Therefore, Beel Bhaina (Beel is the local name of tidal basin), Beel Khukshia, Beel Kaderia, Beel Baruna, Beel Madhugram, Beel Singa etc. have been experiencing water-logging since mid-1980s by the consequences of coastal polders.

The resulted water-logging causes serious damage to agriculture, forestry, fisheries, physical infrastructures and thereby impact on livestock [14]. The area suffers from scarcity of pure drinking water, sanitation system and utility services, as well as squeezed educational and recreational facilities. These types of ecological and societal complexities affecting millions of people during the past two decades under the realm of employment, livelihoods and national economy [15]. Another study by Masud et al.[16] captures the impact of water-logging on biodiversity. It shows that water-logging reduces the number birds, fisheries and livestock as well as retard vegetation and plants growth in the study area. Climate change induced waterlogging and contamination of surface water, soil acidity and water salinity are the principle issues that have a serious and prolonged impact on specious diversity, rangeland and pasture productivity[17].

Tidal River Management (TRM) is a community-based water resource management technique, which is now frequently being practiced in the southwestern coastal region of Bangladesh [1720]. Their judgment is that if tidal flows can be allowed to enter inside the beel, the navigability of the rivers will be restored, and sediment will accumulate inside the polders. As a result, the level of land of beels will rise and generate the enclosed beels free from water-logging while improve the environment by TRM [21]. Besides, the people must pass miserable life because not to introduce agriculture, damage homestead garden, reduce plants, trees, livestock and decline other livelihood options by saline intrusion during TRM period until the land raised enough as the tidal basin flooded two times in a day. Although TRM decreases ecosystem services only for tidal basin during implementation phase, it improves livelihoods by enlarging ecosystem services to the whole catchment area. Moreover, TRM explores an improved socio-agro-ecological system that supports agriculture, forestry, fisheries livestock and other income generating sources to the tidal basin after ending its operation.

Hence, the tidal river-floodplain system and its ecological environment and human wellbeing thereafter are closely interlinked, which has again been aggravated by structural intervention processes $[13,20,22]$. In addition, coastal people choice TRM option (has already been implemented) at Beel Kaderia (1997-2001), East Beel Khukshia (2007-2013) and Beel Kaderia (2002-2005) under Hari-Teka tidal river basin to remove water-logging from floodplain, raise beel by managing sediment and develop drainage capacity of the tidal river as to improve their livelihoods and household's income with offering more ecosystem services. The proper interaction between land and water for allocating rights to use land and water resources concerned with pastoral livelihood, leading protection of crops, trees, settlements and other resources make coastal people to involve livestock rearing with high magnitude and other income generating activities [23]. TRM formulates the management of tidal river-floodplain ecosystem to support livestock with grazing land, fodder and usable water in the coastal region. The study selects Bhaina tidal basin of Southwest Bengal delta from Ganges-Brahmaputra floodplain to identify the impact of TRM on livestock. It attempts to assess the impact of TRM on livestock and its contribution to household's income considering 3 scenarios of TRM (before TRM, during TRM and after TRM).

\section{Actors Involvement in TRM}

TRM is needed to improve the water and sediment regime with a view to keeping them functioning by flushing the sediment inside the depressed tidal basin. In general, the government authority Bangladesh Water Development Board (BWDB for structural support of TRM operation), Center for Environment and Geographic Information Services (CEGIS for mapping and evaluating TRM), Institute of Water Modeling (IWM for monitoring hydro-morphological change of tidal basin and tidal river during TRM) Local Government and Engineering Department (LGED for providing different service facilities), local government (for supporting compensation), GOs and NGOs (for monitoring and supporting the general people) and the community (to raise their voice against corruption, mismanagement for proper functioning) are the main actors engaged in TRM of a region[24]. Since TRM comes from the civil society as a community initiative to control the natural flow of river water, let the sediment inside the tidal basin and removing the water-logging problem but there are no active authorities here. The major decision comes from the community level to induce sediment inside the beels through cut point. Besides, there are some community-based organizations (CBOs) in the locality named "Krishok Songram Somitty", "Water Management Committee", "Pani Committee" and "Beel Management Committee" etc. and it needs strong coordination among GOs, NGOs and CBOs to get substantial benefits from TRM.

\section{Research Gap}

There are several researches in the contemporary literature which deal with the mechanism, characteristics, operating options, conflicts, consequences and sustainability impact of TRM on coastal livelihood have been conducted in the study area[25-27]. Furthermore, they relate TRM to climate change adaptation, agriculture, fisheries, food security, biodiversity, disaster management, sustainable livelihood and coastal zone management. For this reason, the study finds out the following research gaps are as mentioned-They do not capture the impact of TRM on livestock regarding three events of TRM.The contribution of livestock to household's income is not exhibited.

\section{Objectives of the Study}

This paper fixes the following objectives to fill out the research gaps. 
a. To assess the impact of TRM on livestock.

b. To measure the contribution of livestock to household's income and

c. To analyze the effect of salinity on livestock at village level during TRM operation.

\section{Materials and Methods}

\section{Selection of the Study Area}

The study selects three adjacent villages of Bhaina tidal basin purposively, which are affected with salinity in varying degree during TRM implementation phase. These three villages are situated in Keshabpur sub-district under Jessore district (Figure 1). To make a comparison of the effect on livestock during TRM implementation phase, the study selects Sholgatia village of Dumuria sub-district under Khulna district, which has not been affected with salinity intrusion. It is fact that this village is far from the tidal basin and has no tidal effect to this village during TRM operation.

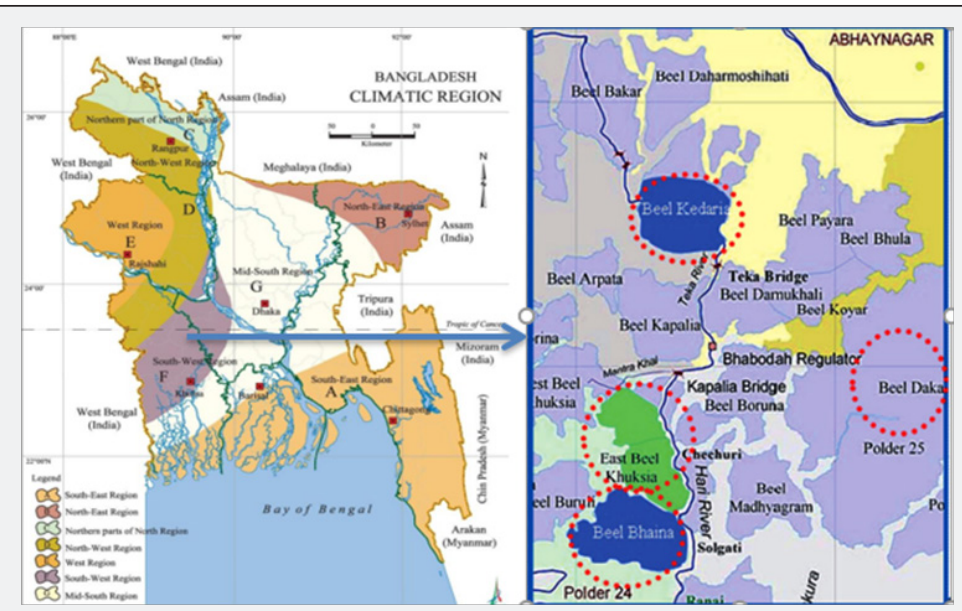

Figure 01: TRM practices at Beel Bhaina and other beels in the study area under Jessore and Khulna districts of Bangladesh (source: Mutahara et al. 2018).

Figure 1 exhibits Map of TRM beels (Beel Bhaina, East Beel Khukshia and Beel Kaderia) and Beel Dakatia where TRM has been implemented through Hari-Teka River from 1997 to 2013 and Hamkura River from 1991 to 1994 respectively under Southwest region of Bangladesh.

\section{Data Sources}

This study collects primary data from interview schedule technique, Key Informant Interview (KII) and Focus Group Discussion (FGD) technique. In addition, secondary data are gathered from reports of government- and non-government organizations as well as from published journal articles.

\section{Sample Size Determination}

Farmers who bearing more than 60 years old and have less than 200 decimals of cultivable land at Bhaina tidal basin are the target population in this study. The sample unit is the households, who are considered for primary data collection. Field survey shows that on an average $75 \%$ of the households in the studied villages comprise less than 200 decimals of cultivable land. The sample size (n) is determined by following the equation given by Kothari (2004).

$$
\mathrm{n}=\left(\mathrm{z}^{2} \mathrm{pqN}\right) /\left(\mathrm{e}^{2}(\mathrm{~N}-1)+\mathrm{z}^{2} \mathrm{pq}\right)----
$$

Where, $\mathrm{z}=$ the value of standard variate at a given confidence level (for 95\% confidence level, $\mathrm{z}$ is 1.96); $\mathrm{p}$ = sample proportion (for $10 \%$ household, $\mathrm{p}$ is 0.1 ); $\mathrm{q}=1-\mathrm{p}$ ( $\mathrm{q}$ is 0.9 ); $\mathrm{N}=$ population size of the village; $\mathrm{e}=$ acceptance error (within $5 \%$ true value, $\mathrm{e}$ is 0.05 ).

This paper follows stratified random sampling to select households for interview schedules. It includes 115 households from target households. Table 1 provides sample size distribution of several villages at Bhaina tidal basin. It involves the maximum 50 households from Agarhati village and the minimum 17 households from Duhuri village. Besides, farmers are in the focus point for FGD. Members of the beel management committee, people's representative of local government, teachers, agrobusiness men and other local elites who have good knowledge about Beel Bhaina are identified for KII. The study comprises 5 FGD and 8 KII at Bhaina tidal basin.

Table 1: Distribution of Sample.

\begin{tabular}{|c|c|c|c|}
\hline $\begin{array}{c}\text { Name of the } \\
\text { Village }\end{array}$ & $\begin{array}{c}\text { Total } \\
\text { Households }\end{array}$ & $\begin{array}{c}\text { Target } \\
\text { Households }\end{array}$ & Sample Size \\
\hline Sholgatia & 160 & 120 & 20 \\
\hline Duhuri & 132 & 100 & 17 \\
\hline Sarutia & 220 & 165 & 28 \\
\hline Agarhati & 400 & 300 & 50 \\
\hline & \multicolumn{2}{|c|}{ Total Sample Size } & 115 \\
\hline
\end{tabular}

\section{Analytical Tools and Technique}

With a view to capturing the impact of TRM on livestock, present study considers three scenarios of TRM. Following 
subsections make a temporal analysis about the impact of TRM on livestock. Before TRM implies the time when water-logging has not been appeared in the area as the cause of human suffering. It was the normal period when people of the area did not feel the urgency of implementing TRM. It was the time from 1960 s to early 1980s (without water-logging) and mid-1980s to 1996 (with water-logging) for this tidal basin. During TRM implies the time when TRM was being implemented. It was from 1997 to 2001 for this area. This phase is again characterized by inter temporal component about salinity intrusion. Field survey shows that salinity intrusion is a major factor determining the impact of TRM on livestock during implementation phase. This is due to the reason that salinity affects different area by different degrees depending on the location of the village and proximity of that village to the tidal river. After TRM period starts from the time when the implementation of TRM has been completed; from 2002 to 2016. Following sub-sections will address the impact of TRM on livestock regarding different scenarios of TRM.

Present study captures the impact of TRM on livestock holding in terms of number and percentage. It includes 8 main species of livestock i.e. hen, duck and goose (3 bird animals) and goat, sheep, cow, buffalo and horse (5 four legged animals) of the Southwest delta of Bangladesh. Field level data on the number of livestock has been collected for the assessment of impact. This paper involves five-pointscale (disagree, strongly disagree, neutral/no comments, agree and strongly agree) to extract opinion form farmers in FGD regarding qualitative data. It collects data on grazing land, fodder, soil quality and water quality relation with salinity etc. from FGD.The underlying reasons behind the changes in the livestock have also been analyzed in this study.

\section{Result and Discussion}

\section{Assessing the Impact of TRM on Livestock in the Tidal Basin}

Local people in Bhaina tidal basin introduced TRM as an indigenous and eco-friendly technique during the period of 1997-2001. Lives and livelihoods of the people dependent on Bhaina tidal basin have changed greatly due to implementation of TRM. Field survey shows that impacts of TRM in the study area are dynamic, which links peoples' lives and livelihoods with three different scenarios of TRM. TRM, in that area was basically implemented with a view to solving water-logging problem in the tidal basin and removing drainage congestion of the Hari River[28,29]. TRM connects the rivers with tidal basin through different connecting channels, which allows the river water coming into and coming out from the tidal basin two times per day. This process not only allows depositing sediments in the tidal basin, but also increases river's water reservation capacity and navigability.

During TRM implementation period, this technique is supposed to alter the livestock of the tidal basin. These changes have been more profound in an open TRM, which has been followed by Bhaina tidal basin. Under the open TRM, village protection dam was not built in the area, which allowed intruding saline water even into the homestead land. Intrusion of saline water both in the tidal basin and the homestead land changed the structure of household production for basic sustenance and access to cash income through altering the access to rearing livestock. During TRM implementation phase, people in the adjacent locality of Bhaina tidal basin captured its' impact in terms of reduced access to livestock, fisheries, and fruit and timber trees, which generally are the sources of household production and cash income. It is important to mention that people enjoyed a reliable access to the household production and cash income during 1980s, which was the normal time before water logging appears in this tidal basin. However, the cost incurred by the people during TRM implementation phase must be outweighed by the increased benefits obtained by them after TRM implementation phase. Against this backdrop, this research attempts to make a comparison among three different scenarios of TRM with reference to its' impact on livestock in the adjacent villages of Bhaina tidal basin.

Table 2 shows changes in the number of livestock in different scenarios of TRM. Except sheep, all other varieties of livestock have reduced at different rates during TRM implementation phase, but again increased after TRM phase. Quantity of livestock increases even more than before TRM phase, which may be the manifestation of comparatively better living standard after TRM implementation phase.

Table 2: The total number of livestock in different TRM at Bhaina tidal basin.

\begin{tabular}{|c|c|c|c|c|c|c|}
\hline $\begin{array}{c}\text { Different } \\
\text { TRM }\end{array}$ & Hen & Duck & Goose & Goat & Sheep & Cow \\
\hline Before TRM & 209 & 469 & 17 & 96 & 6 & 188 \\
\hline \multirow{2}{*}{ During TRM } & 135 & 237 & 13 & 71 & 9 & 145 \\
\cline { 2 - 7 } & $(-35 \%)$ & $(-49 \%)$ & $(-24 \%)$ & $(-26 \%)$ & $(+50 \%)$ & $(-23 \%)$ \\
\hline \multirow{2}{*}{ After TRM } & 378 & 604 & 23 & 162 & 24 & 274 \\
\cline { 2 - 7 } & $(+81 \%)$ & $(+57 \%)$ & $(+35 \%)$ & $(+69 \%)$ & $(+300 \%)$ & $(+46 \%)$ \\
\hline
\end{tabular}

N.B.: Changes are calculated considering 'before TRM' situation as the base.

In every case, the number of livestock is declined except sheep during TRM event regarding before TRM event. It is increased by $50 \%$ and proves that salinity has no negative effect on sheep production. The highest $49 \%$ is decreased for duck at this time. Buffalo and horse are not found in the study area. Duck and cow were more popular livestock than hen and goat. Besides, pet animals- cats and dogs were declined more than $50 \%$ during TRM but increased by more than $20 \%$ after TRM. For bird animals, duck reaches the top number (604) which followed by hen number (378). In addition, for four legged animals, cow extends the peak number (274) that followed by goat number (162) after TRM scenario comparing to before TRM scenario. He is progressed by $81 \%$ and goat is advanced by $69 \%$ respectively for bird animals and four legged animals after TRM phase considering before TRM phase. 
Figure 2 includes the opinion of respondents at five-point scale from focus group discussion for the statement that 'reduces of grazing land' and 'availability of fodder' for comparing after TRM event to before TRM event. It exhibits that $20 \%$ respondents are strongly agree, $60 \%$ respondents are agreed, and $20 \%$ respondents have no comments for the statement 'reduces of grazing land' at Beel Bhaina. Besides, $80 \%$ respondents are strongly agreed, and $20 \%$ respondents are agreed for the statement 'availability of fodder' at Bhaina tidal basin.

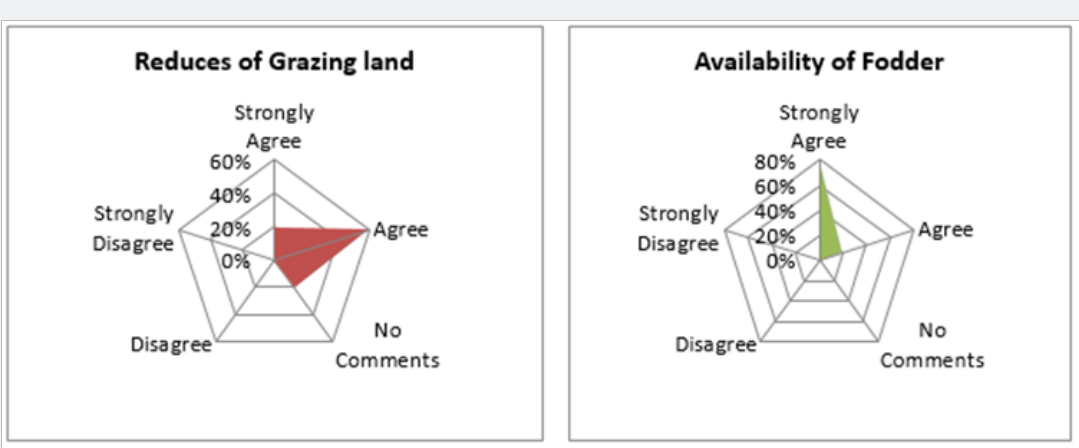

Figure 2: The opinion of farmers (in percentage) regarding water pollution and fodder after TRM phase at Beel Bhaina.

Grazing land reduction is alarming for pastoral livelihood though fodder is available for livestock in this area. An intensive change in agricultural pattern has been happened after TRM phase as compare to before TRM phase. Paddy lands are converted in to fish farms as farmers wish to get more financial benefits. Aus (pre-monsoonal variety of paddy) and Aman (monsoonal variety of paddy) are rarely found except Boro (post monsoonal variety of paddy). There is no fallow land and fish is cultivated all over the year. Therefore, grazing land is decayed largely in the Bhaina tidal basin after TRM implementation phase. Besides, double crops are introduced in the land at the same time i.e. fish with vegetables and paddy with vegetables. Vegetables are grown on the Veri (high land is surrounded of the farm) and fish/paddy is cultivated in the main land of the farm. Sometimes, there are no vegetables on the Veri where grass, plants and other herbs are grown naturally. For this reason, fodder is available in the Beel.

\section{Measuring the Contribution of Livestock to House- holds' Income}

Table 3: Monthly income of households generated from livestock.

\begin{tabular}{|c|c|c|c|c|c|c|}
\hline $\begin{array}{c}\text { Different } \\
\text { TRM }\end{array}$ & Hen & Duck & Goose & Goat & Sheep & Cow \\
\hline $\begin{array}{c}\text { Before } \\
\text { TRM }\end{array}$ & 10450 & 23450 & 1700 & 28800 & 1800 & 188000 \\
\hline $\begin{array}{c}\text { During } \\
\text { TRM }\end{array}$ & 6750 & 11850 & 1300 & 21300 & 2700 & 145000 \\
\cline { 2 - 7 } & $(-35 \%)$ & $(-49 \%)$ & $(-24 \%)$ & $(-26 \%)$ & $(+50 \%)$ & $(-23 \%)$ \\
\hline \multirow{2}{*}{$\begin{array}{c}\text { After } \\
\text { TRM }\end{array}$} & 18900 & 30200 & 2300 & 48600 & 7200 & 274000 \\
\cline { 2 - 7 } & $(+81 \%)$ & $(+29 \%)$ & $(+35 \%)$ & $(+69 \%)$ & $(+300 \%)$ & $(+46 \%)$ \\
\hline
\end{tabular}

NB: Changes are calculated considering 'before TRM' situation as the base.

Table 3 involves the amount of income generated from livestock by the households. Respondents in the study area make greater cash income after TRM implementation scenario than the other two scenarios of TRM. After TRM phase is associated with more favorable environmental condition for rearing and further investing in the livestock. Gross income from livestock increases by 50 percent after TRM being implemented. Species specific increases range from $29 \%$ up to $300 \%$ in the study area. Greater increase captured in case of sheep although they are fewer in absolute number. Second highest increase in income comes from hen followed by goat, cow, goose and duck respectively. But during TRM phase, greater decrease in income captured in case of duck followed by hen, goat, goose and cow correspondingly.

\section{Before TRM}

Present study measures the impact on number of and access to livestock resources. In this phase, people enjoyed easy access to livestock resources. Households owned sufficient number and diverse category of livestock. At that time, grazing land was available, which ensures sufficiency of food and fodder. People had cash money generating from livestock selling, which again became a source of investment in livestock resources.

\section{During TRM}

This phase squeezed both the number and variety of livestock resources. This is due to the reason that TRM implementation phase reduced the availability of grazing land as agricultural land (Beel) and in many cases homestead lands were under waterlogged. This situation created the scarcity of fodder for livestock. Livelihood displacement by land inundation shrunk the opportunity to generate cash income from livestock selling and reduced the capacity to further invest in livestock at that phase.

\section{After TRM}

After TRM implementation phase, increased productivity of both land and labor force creates favorable environment for livestock rearing as land are no more inundated and labor forces become employed within the local area. Increase in productivity enhances peoples' capacity to expand household production; greater amount of cash money holding enables the households to purchase and invest in increased number and variety of livestock. Figure 3 captures the total households' income from livestock for 
before TRM, during TRM and after TRM scenarios at Bhaina tidal basin. It provides that households' income was reduced by $26 \%$ during TRM case and improved by $50 \%$ after TRM case in view of before TRM case.

Figure 4 comprises three main sources (i.e. agriculture, livestock and day labor) of household income of a poor farmer. It demonstrates that the contribution of livestock regarding households' income was dropped by $2 \%$ both for during TRM and after TRM events. In addition, the role of agriculture (paddy, fisheries and vegetables are in together) to households' income was increased by $11 \%$ after TRM event regarding before TRM event. Besides, the support of day labor to household's income was reduced by $9 \%$ after TRM event comparing to before TRM event. Since households' income was progressed by $50 \%$ from livestock (Figure 3), as a source, the contribution of livestock to households' income was fall down by $2 \%$ after TRM event relating to before TRM event.

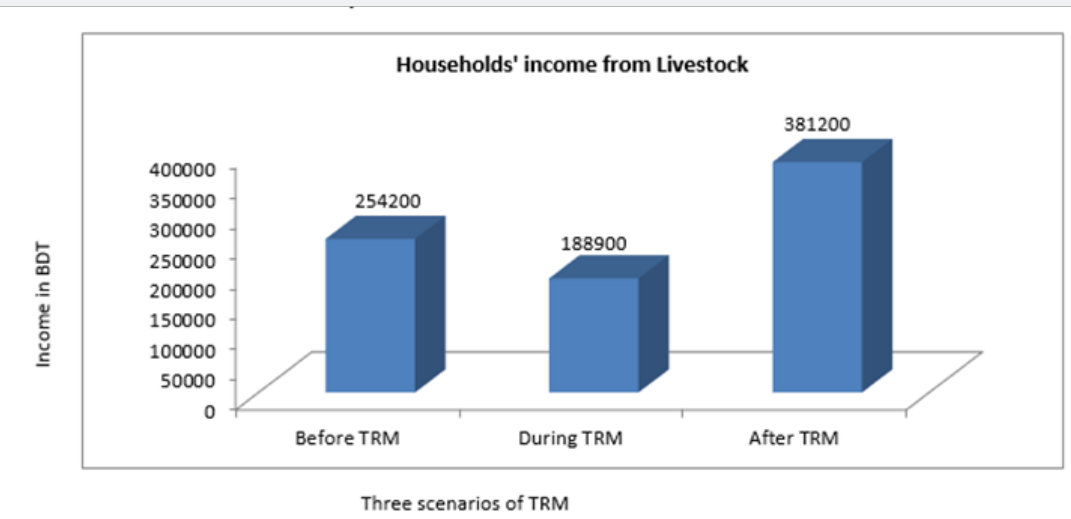

Figure 3: The contribution of livestock to households' income in different scenarios of TRM at Beel Bhaina.

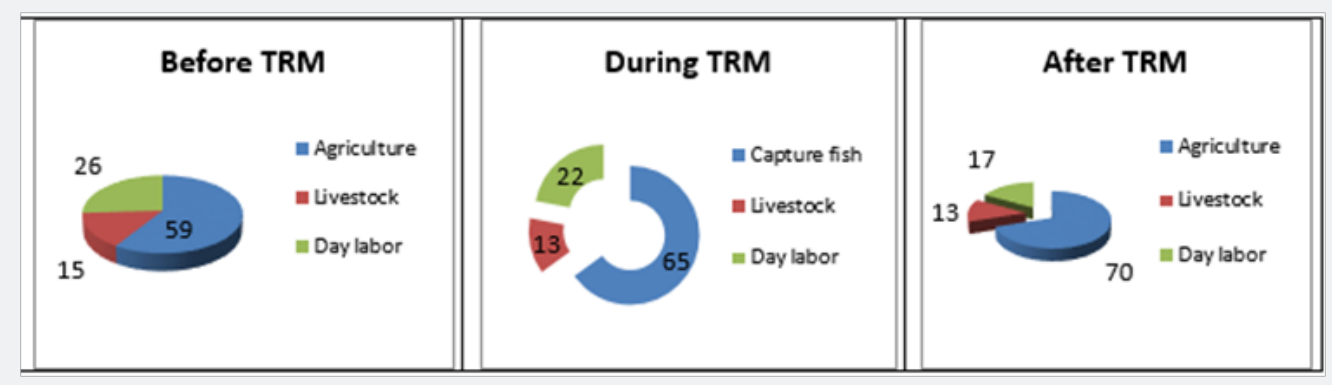

Figure 4: The contribution to the households' income of different sources (in percentage) for several TRM events at Beel Bhaina.

Capturing the Effect of Salinity on Livestock During TRM Implementation Phase

To capture the effect on livestock during TRM implementation phase, the study selects three types of villages depending on the severity of salinity in the study area. Village wise salinity types are presented below: Sholgatia (Unaffected); Duhuri (Medium to Strong affected); Sarutia (Medium to Strong affected); Agarhati (Low to Medium affected). Except for Sholgatia village, salinity affects both soil and water quality in all other villages in the study. It has already mentioned that Beel Bhaina followed the open TRM system, under which no village protection dam was built surrounding the villages. For this reason, saline water intruded inside the locality of the adjacent Hari River. Therefore, the villages which situated close to the river have been affected by salinity with different degree. It is important to note that during TRM phase is characterized by decrease of all components of livestock except Sheep. Salinity intrusion remains an added disadvantage for villages adjacent with the river because the rate of decrease of livestock is even more in these places. All the respondents in the studied villages acknowledged that salinity level has increased in both water and soil quality of the Beel, homestead land and of the pond (Figure 5).

Figure 5 involves five components (pond's water, beel's water, canal's water, homestead's soil and beel's soil) of environment in the context of effect of salinity during TRM operation phase. It extracts opinion from farmers for the statement 'increases of salinity' considering these five components. It illustrates that $100 \%$ respondents are strongly agree for the statement 'increases of salinity' during TRM scenario regarding before TRM scenario. Besides, $60 \%$ respondents are strongly agreed, and $40 \%$ respondents are agreed for the statement 'decreases water pollution' after TRM scenario concerning before and during TRM scenarios in the study area. These opinions follow the results of Table 2, the number and presence of livestock are 
reduced during TRM event due to scarcity of food and fodder and vanishing grazing land. In addition, rearing of livestock is developed after TRM event basis of improving accessibility of livestock to grazing land and availability of food and fodder by agricultural intensification at Bhaina tidal basin.

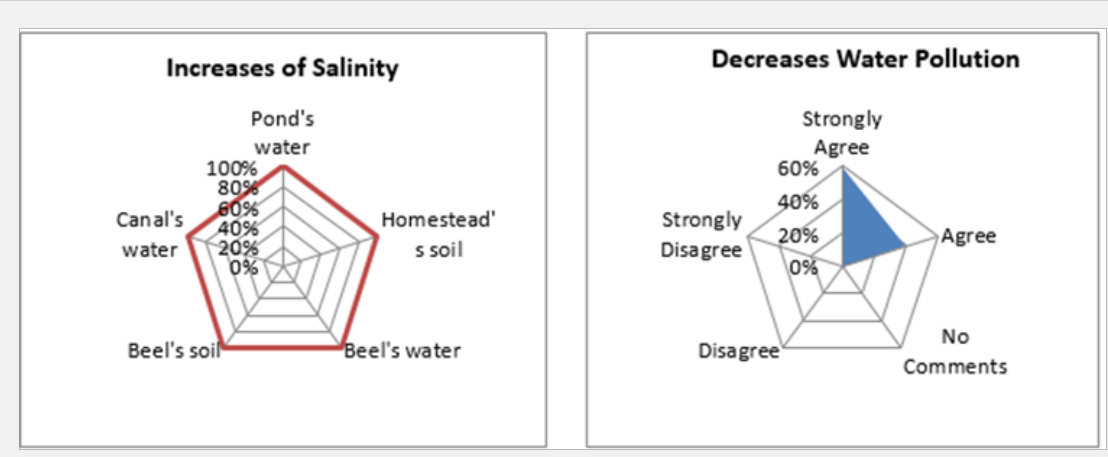

Figure 5: The contribution to the households' income of different sources (in percentage) for several TRM events at Beel Bhaina.

Table 4 below shows the impact of salinity on livestock during TRM implementation phase. Greatest difference between the two-time period (before and during TRM) has been exhibited in case of duck, followed by hen, goat and cow in Duhuri village. Except Sholgatia village, duck is the most affected species during TRM phase for all the cases followed by hen, cow and goat. There

Table 4: Changes in the livestock of three TRM phases at Beel Bhaina. was no duck found at Duhuri village. Furthermore, duck was declined by $50 \%$ more at Sarutia and Agarhati villages at this time. Therefore, it is evident from the study that salinity has a negative implication both in number and persistence of livestock at these villages.

\begin{tabular}{|c|c|c|c|c|c|c|c|}
\hline Name of the Village & Different TRM & Hen & Duck & Goose & Goat & Sheep & Cow \\
\hline \multirow{3}{*}{ Duhuri (Medium to Strongly Affected) } & Before TRM & 66 & 50 & 2 & 34 & 0 & 21 \\
\hline & During TRM & 34 & 0 & 0 & 11 & 0 & 10 \\
\hline & After TRM & 115 & 125 & 9 & 49 & 7 & 21 \\
\hline \multirow{3}{*}{ Sarutia (Medium to Strongly Affected) } & Before TRM & 57 & 115 & 11 & 18 & 0 & 15 \\
\hline & During TRM & 15 & 28 & 13 & 10 & 0 & 10 \\
\hline & After TRM & 93 & 134 & 14 & 32 & 7 & 25 \\
\hline \multirow{3}{*}{ Agarhati (Low to Medium Affected) } & Before TRM & 51 & 196 & 4 & 4 & 0 & 107 \\
\hline & During TRM & 25 & 79 & 0 & 7 & 0 & 78 \\
\hline & After TRM & 75 & 183 & 0 & 11 & 0 & 165 \\
\hline \multirow{3}{*}{ Sholgatia (Unaffected) } & Before TRM & 61 & 108 & 0 & 40 & 6 & 45 \\
\hline & During TRM & 61 & 130 & 0 & 43 & 9 & 47 \\
\hline & After TRM & 95 & 162 & 0 & 70 & 10 & 63 \\
\hline
\end{tabular}

Field survey demonstrates that goose (found in 3 villages out of 4) and sheep (found in 1 village out of 4) were rare livestock species at Bhaina tidal basin for before TRM case. Goose was further reduced and found in 1 village out of 4 villages during TRM operation case.In addition, goose (found in 2 villages out of 4) and sheep (found in 3 villages out of 4) were progressed in number and presence during TRM implementation phase after TRM case considering before TRM case. Moreover, hen was plunged by $60 \%$ more at Sarutia village and $50 \%$ at Duhuri and Agarhati villages during TRM event matching to before TRM event. From before TRM event to during TRM event, goat was decreased by 50\% more at Duhuri village and 50\% less at Sarutia village but increased by $50 \%$ more at Agarhati village. Furthermore, cow was dropped by $50 \%$ more at Duhuri village and $30 \%$ more at Sarutia and Agarhati villages during TRM phase comparing to before TRM phase. Although all livestock species were decreased (exception for goose at Sarutia and goat at Agarhat villages) during TRM implementation case due to salinity these were increased both in number and survival after TRM implementation case (removal of saline effect) bearing in mind before TRM case.

\section{Conclusion}

Nature governs the people and people understand the nature well. Peoples' livelihood in the Ganges-Brahmaputra basin is closely linked with natural resource, environmental features and the processes continuing from generation to generation. TRM comes to light as people's traditional wisdom for coastal 
river basin management. When number of governmental and non-governmental bodies failed to manage costal land and water regime then Tidal River Management (TRM) seem to be an effective and sustainable way to reform the coastal dynamics. TRM has some socio-ecological impact on coastal livelihood where impact on livestock and the generated income level before, during and after TRM are a vital part of rangeland management. The study found that water-logging condition exerts negative impact on livestock. Likewise, TRM operational period limits the scope of animal husbandry and the income generated from livestock rearing thereby.

In both cases, it was due to the scarcity of food and fodder sources and damaging grazing land, which must need attention for providing substitute option for rearing livestock and generating alternative income and protein sources to pastoral community. However, it has been found that after TRM phase generates more scope for livestock rearing due to intensification of agricultural activities and increasing homestead vegetation. Notwithstanding the fact, this paper does not include egg, milk and meat production, and technological improvement and accessibility to livestock as the alternative way to assess the impact. The findings from this study support policy makers to take effective decision for the improvement of livestock and other ecosystem services to rural community in the context of water resources management in coastal region. This research encourages further researches to link TRM with livestock, fisheries, agriculture, forest, biodiversity and other income generating activities to households for sustainable pastoral livelihood to achieve sustainable development goals.

\section{References}

1. Lardy G, Stoltenhow C, Johnson R (2008) Livestock and Water. North Dakota State University, Fargo, North Dakota, USA.

2. Lynch R (2012) A guide to managing and restoring wetlands in Western Australia Livestock. Managing wetlands. Australia.

3. Steinfeld H, Gerber P, Wassenaar T, Castel V, Rosales M, et al. (2006) Livestock's long shadow. Environmental issues and options. FAO. Rome, Italy.

4. Chapagain AK, Hoekstra AY (2003) Virtual water flows between nations in relation to trade in livestock and livestock products. Value of Water Research Report Series No 13. Institute for Water Education, UNESCO-IHE. Delft Netherlands.

5. Nyachieo J (2016) Promising practices in supporting management of water resources in pastoral areas. Agriculture and Food Security Network, Australia.

6. Islam SMD, Bhuiyan MAH, Ramanathan AL (2015) Climate change impacts and vulnerability assessment in coastal region of Bangladesh: A case study on ShyamnagarUpazila of Satkhira district. Journal of Climate Change 1(1,2): 37-45.

7. Islam SN (2016) Deltaic floodplain development and wetland ecosystem management in Ganges-Brahmaputra-Meghna River Delta in Bangladesh. Sustainable Water Resources Management 2(3): 237256.

8. Van Laarhoven J, Scholz G, Phipps L, Favier D (2004) A river management plan for the Light Catchment.
9. Cadoret A (2009) Conflict dynamics in coastal zones: a perspective using the example of Languedoc-Rousillon (France) Journal of coastal conservation 13(2-3): 151 .

10. Miah G, Bari N, Rahman A (2010) Resource degradation and livelihood in the coastal region of Bangladesh. Frontiers of Earth Science in China 4(4): 427-437.

11. Cooke GD, Welch EB, Peterson S, Nichols SA (2016) Restoration and management of lakes and reservoirs. CRC press, USA.

12. Datta DK, Ghosh PK (2015) Groundwater of the municipalities of southwestern coastal Bangladesh. Surface and Sub-surface Water in Asia: Issues and Perspectives pp. 120-145.

13. Gain AK, Benson D, Rahman R, Datta DK, Rouillard JJ (2017) Tidal river management in the south west Ganges-Brahmaputra delta in Bangladesh: moving towards a transdisciplinary approach? Environmental Science and Policy 75: 111-120.

14. Haider MZ, Moni NN (2008) Consequences of Water-logging: A Study on the Southwest Region of Bangladesh. Plan Plus 5(1): 26-40.

15. Rahman S, Rahman SH, Ullah MW (2000) Assessment of Water-logging extent using RS and GIS techniques and its possible remedial measures at the Kopotaksho basin area, Bangladesh.

16. Masud MMA, Moni NN, Azad AK (2014) Impacts of Water-logging on Biodiversity - Study on Southwestern Region of Bangladesh. IOSR Journal of Environmental Science, Toxicology and Food Technology 8(9): 20-27.

17. BRS (2001) Environmental Factors Affecting Australia's Livestock Industries. A BRS report for Meat and Livestock Australia, Bureau of Rural Sciences (BRS), Australia.

18. Tutu AA (2005) River Management in Bangladesh: a People's Initiative to Solve Water-logging, Coastal Development Partnership (CDP), Khulna, Bangladesh, Participatory Learning and Action 51: 117-123.

19. Dewan C (2012) Review of the historical evolution of policies and institutions of community-based management in coastal Bangladesh, G3: Water Governance and Community Based Management, IWMI (International Water Management Institute).

20. Masud MMA, Moni NN, Azadi H, Van Passel S (2018)Sustainability impacts of tidal river management: Towards a conceptual framework, Ecological Indicators 85: 451-467.

21. Amir MSII, Khan MSA, Khan, MMK, Rasul MG, Akram F (2013) Tidal river sediment management: a case study in Southwestern Bangladesh. Int Journal of Civil Science and Engin, World Academy of Science, Engineering and Technology 7(3): 861-871.

22. Paul A, Nath B, Abbas MR (2013) Tidal River Management (TRM) and its implication in disaster management: A geospatial study on Hari-Teka river basin, Jessore, Bangladesh. International Journal of Geomatics and Geosciences 4(1): 125.

23. Nassef M, Ludi E (2012) Providing and managing water in Ethiopia's pastoral regions: lessons learned over the past 40 years. Addis Ababa: Save the Children USA.

24. Edrish MB, Yeasmin S, Rahman S (2017) Impact of Tidal River Management (TRM) On the Livelihood Pattern of Local People: A Case Study of Gaurighona Union, KeshabpurUpazilla, Jessore, Journal of Bangladesh Institute of Planners 9: 43-58.

25. Shampa, Pramanik IM (2012) Tidal River Management (TRM) for Selected Coastal Area of Bangladesh to Mitigate Drainage Congestion. International Journal of Scientific and Technology Research 1(5): 2277-8616.

26. Karim R, Mondal R (2017) Local Stakeholder Analysis of Tidal River Management (TRM) at BeelKapalia and the Implication of TRM as a Disaster Management Approach. Hydrology 5(1): 1. 
27. Mutahara M, Warner JF, Wals AE, Khan MSA, Wester P (2018) Social learning for adaptive delta management: Tidal River Management in the Bangladesh Delta. International Journal of Water Resources Development 1-21.

28. Rahman A (1995) BeelDakatia: The Environmental Consequences of a Development Disaster, University Press Limited Dhaka.
29. CEGIS (2007) Environmental and Social Impact Assessment of the Proposed Project "Removal of Drainage Congestion from the Beels adjacent to Bhabadaha area under Jessore District (phase-1). Bangladesh Water Development Board, Dhaka, Bangladesh.
This work is licensed under Creative Commons Attribution 4.0 License DOI: 10.19080/JDVS.2018.06.555696 